\title{
A Case-control Study of Prevalence of Cholelithiasis among Type 2 Diabetic Patients in Kashmir.
}

\author{
Shakeeb Nabi ${ }^{1}$, Zhahid Hassan², Syed Nazima ${ }^{3}$, Hakim Vaqar ${ }^{1}$ \\ 'Department of General and Minimal Access Surgery GMC Baramulla, ${ }^{2}$ Department of Endocrinology GMC Baramulla, ${ }^{3}$ Department of Anaesthesia GMC \\ Baramulla.
}

\section{Abstract}

Background: Type 2 Diabetes mellitus and gall bladder stones are both common and co-existent diseases in a significant population. Increasing age, female gender, overweight, fair skin, familial history of the disease and type 2 diabetes mellitus is all associated with an increased risk of gallstones. Several studies from around the world reported an increased prevalence of gall bladder stones in patients with diabetes mellitus. Aims and objectives: The aim of this study was to define the frequency of gall bladder stones among diabetics and to evaluate the possible associated risk factors in these patients. Subjects and Methods: A case control study was performed during 2018 at Government Medical College Baramulla. The study involved 161 randomly selected type-2 diabetic patients under regular follow up at the center, and 166 age and sex matched non-diabetic outpatients. Real-time abdominal ultrasound was performed by a radiologist to examine the abdomen after an overnight fast. Results: About $40 \%$ of the diabetic cohort had gall bladder stones as compared to $17.5 \%$ of non-diabetic patients. Females were significantly more affected than males. Patients with gall bladder stones were significantly older and had a significantly higher body mass index than those without stones. Conclusion: The prevalence of gallstones in diabetic patients is higher in Kashmir than the rates reported in other parts of the world. Kashmiri diabetic patients with gallstones tend to be older and more obese than those without gallstones. Duration of diabetes mellitus and type of treatment does not seem to influence the frequency of gall bladder stones among Kashmiri diabetics.

Keywords: Cholelithiasis, Type 2 Diabetes Mellitus.

Corresponding Author: Dr. Zhahid Hassan, Department of Endocrinology GMC Baramulla.

Received: June 2019

Accepted: June 2019

\section{Introduction}

In Western countries the presence of gallstones increases with age, with a prevalence approaching $30 \%$ by age $70 .^{[1,2]}$ The majority of these stones are composed of cholesterol. ${ }^{[3]}$ The etiology of cholesterol gallstones is multifactorial, and a number of risk factors have been identified. These include age, sex, genetic factors, obesity, parity, diet, drugs, hyperlipidemia, and ileal resection. ${ }^{[4]}$ Diabetes is often mentioned as a risk factor but the evidence has been conflicting. A number of autopsy studies have been performed, some showing an increased prevalence of gallstones in diabetics while others have shown no such association. ${ }^{[5-9]}$

Diabetes mellitus (DM) and gall bladder stones (GBS) are both common and costly diseases. In general, GBS are more frequent in females due to hormonal factors. Increasing age, being overweight, family history of GBS and type 2 DM are all associated with an increased risk of gallstones. ${ }^{[10]}$ Several studies from across the world reported an increased prevalence of GBS in patients with DM. ${ }^{[14-18]}$ How diabetes predisposes to gallstones is not well understood. However, hypertriglyceridemia, autonomic neuropathy (leading to gallbladder hypomotility and biliary stasis) and hyperinsulinemia have been suggested as contributing factors to the increased risk of GBS development in diabetics. ${ }^{[10,13,14]}$ An Italian study showed that the prevalence of gallstone disease is significantly higher in diabetic patients than in the general population $(24.8 \%$ vs.13.8\%). ${ }^{[15]}$ Another study from New Zeeland reported a GBS prevalence of $32.7 \%$ among diabetic patients as compared to $20.8 \%$ in controls. ${ }^{[16]}$ To the best of our knowledge, no data has been reported from Kashmir on the prevalence of GBS, neither in the general population nor in diabetic patients. The aim of this study was to examine the association between diabetes and the development of gall bladder stones.

\begin{abstract}
Aims and objectives
The aim of this study was to determine the frequency of GBS among Kashmiri diabetics in comparison to nondiabetic outpatients and to evaluate the possible associated factors in this high risk group.
\end{abstract}

\section{Subjects and Methods}

A case-control study was performed during 2018. The study involved 161(107 females and 54 males) randomly selected 
type-2 diabetic patients under regular follow at GMC Baramulla. The control group consisted of 166 age and sex matched non diabetic patients (109 females and 57 males) recruited from subjects attending the medical outpatient departmen for checkup. Patients were interviewed to obtain the following information: age, sex, duration of DM, type of treatment, parity, history of cholecystectomy, history of GBS (patients with previous history of GBS were included), type of GBS (single or multiple), use of oral contraceptives, and history of GBS in first degree relatives. Weight and height were measured and body mass index (BMI) was calculated for each patient. Obesity was defined according to $\mathrm{WHO}$ as $\mathrm{BMI} \geq 30 \mathrm{~kg} / \mathrm{m}^{2}$. A radiologist employed realtime ultrasound to examine the abdomen after an overnight fast. Data were analyzed with the Statistical Package for the Social Sciences (Windows version Mac oz; SPSS Inc, Chicago, IL). Data were expressed as mean \pm standard deviation (SD). Differences between groups were evaluated by using the Chi squared test and independent samples ttest. P-values $<0.5$ were considered significant.

\section{Results}

The mean age of the diabetic cohort was $52.5 \pm 11.7$ years ( $50.8 \pm 10.3$ years for females and $56 \pm 13.5$ years for males). The mean age of the control group was $49.5 \pm 19.9$ years ( $47.7 \pm 19$ years for females and $52.7 \pm 21$ years for males). GBS was observed in $39.75 \%$ of the diabetic cohort and in $17.5 \%$ of the control (2.27 times higher), the prevalence was significantly higher in female diabetics than in males

\begin{tabular}{|l|l|l|l|}
\hline Table 1: Comparison between diabetics and control group \\
\hline & DM & NO DM & P-value \\
\hline Number & 161 & 166 & \\
\hline Females & 107 & 109 & \\
\hline Males & 54 & 57 & 0.000 \\
\hline GBS $\%)$ & $39.8 \%$ & $17.5 \%$ & 0.000 \\
\hline GBS \% in F & $46.7 \%$ & $18.3 \%$ & 0.18 \\
\hline GBS \% in M & $25.9 \%$ & $15.8 \%$ & 0.095 \\
\hline Mean age $( \pm$ SD) & $52.5 \pm 11.7$ & $49.5 \pm 19.9$ & \\
\cline { 2 - 4 } & years & Years & 0.14 \\
\hline Mean age of F & $50.8 \pm 10.3$ & $47.7 \pm 19$ & \\
\hline$( \pm$ SD) & years & Years & \\
\hline Mean age of M & $56 \pm 13.5$ & $52.7 \pm 21$ & 0.34 \\
\hline$( \pm$ SD) & years & Years & \\
\hline Multiple GBS & $75 \%$ of all & $72.4 \%$ of all & 0.79 \\
\hline & GBS & GBS & \\
\hline
\end{tabular}

Female $=\mathrm{F}$, Male $=\mathrm{M}, \mathrm{DM}=$ diabetes mellitus, $\mathrm{GBS}=$ gallbladder stone, $\mathrm{SD}=$ standard deviation

The higher prevalence of GBS among females compared to males was more marked in diabetic patients younger than 50 years $(42.5 \%$ vs. $7.7 \%, \mathrm{p}=0.02)$ than in those who were 50 years or older $(51.8 \%$ in females vs. $37.1 \%$ in males, $\mathrm{p}=0.17$ ). In the control group females were also more affected than males $(18.3 \%$ vs. $15.8 \%)$. Diabetic patients with GBS were overall significantly older than those without GBS (mean 55.5 years vs. 50.5 years, $\mathrm{p}=0.007$ ). Similarly, males with GBS were significantly older than their female counterparts. The prevalence of GBS among diabetics progressively increased with age.The age beyond which prevalence of GBS increased significantly was 41 years in females $(\mathrm{p}=0.01)$ and 53 years in males $(\mathrm{p}=0.003)$. There was no significant difference between diabetic patients with GBS and diabetic patients without GBS regarding duration of DM or type of treatment (oral, insulin or both).

Table 2: Comparison between diabetics with GBS and without GBS

\begin{tabular}{|l|l|l|l|}
\hline & Diabetics with & Diabetics & P- \\
\cline { 2 - 4 } & GBS & $\begin{array}{l}\text { without } \\
\text { GBS }\end{array}$ & Value \\
\hline Females & $78 \%$ & $59 \%$ & 0.011 \\
\hline Age & $55.5 \pm 9.7$ years & $\begin{array}{l}50.5 \pm \\
\text { Years } 12.5\end{array}$ & 0.007 \\
\hline DM duration $( \pm \mathrm{SD})$ & $12.5 \pm 7.7$ years & $\begin{array}{l}10.6 \pm \\
6.8 \text { years }\end{array}$ & 0.11 \\
& & $82.2 \pm 16.9$ & 0.33 \\
\hline Mean Weight $( \pm \mathrm{SD})$ & $84.7 \pm 14.9 \mathrm{~kg}$ & $\mathrm{~kg}(51-123)$ & \\
& $(58-124)$ & $32.2 \pm 7.5$ & \\
\hline Mean BMI $( \pm \mathrm{SD})$ & $34.78 \pm 6.29$ & $\mathrm{~kg} / \mathrm{m}^{2}$ & \\
& $\mathrm{~kg} / \mathrm{m}^{2}(21.5-$ & $21.6 \%$ & 0.97 \\
\hline OHG & $55.1)$ & $26.8 \%$ & 0.47 \\
\hline INSULIN & $21.9 \%$ & $46.3 \%$ & 0.30 \\
\hline BOTH & $21.9 \%$ & $27.8 \%$ & 0.07 \\
\hline F/H & $54.6 \%$ & $41.2 \%$ & $\mathrm{~B} \%$ \\
\hline
\end{tabular}

$\mathrm{GBS}=$ gallbladder stone, $\mathrm{DM}=$ diabetes mellitus, $\mathrm{SD}=$ standard deviation, $\mathrm{BMI}=$ body mass index, $\mathrm{OHG}=$ oral hypoglycemic drugs, $\mathrm{F} / \mathrm{H}=$ family history

The mean BMI for diabetics with GBS was significantly higher, 34.78+/-6.29, than the mean BMI for diabetics without GBS, 32.2+/-7.5, $(\mathrm{p}=0.027)$. Risk of GBS increased significantly when BMI was over $24 \mathrm{~kg} / \mathrm{m} 2(\mathrm{p}=0.019)$. Moreover, the mean BMI of diabetic females with GBS was significantly higher than the mean BMI of diabetic males with GBS $(\mathrm{p}<0.001)$. A family history of GBS was found in $40.6 \%$ of patients with GBS and $27.8 \%$ of those without, but it was only in females that the difference ( $48 \%$ vs. $24.5 \%$ ) was significant $(\mathrm{p}=0.011)$. The frequency of GBS progressively increased with number of pregnancies. About $50.5 \%$ of multiparus females had GBS as compared to $10 \%$ of nulliparus $(\mathrm{p}=0.01)$. Mean parity of females with GBS $(10.1+/-3.48$; range: $0-17)$ was significantly higher $(\mathrm{p}=$ $0.010)$ than mean parity of females without GBS $(7.7+/-$ 4.7; range: 0-17). About $44 \%$ of females with GBS were using oral contraceptives as compared to $42 \%$ of females without GBS ( $p=0.84$, both groups had almost the same mean age, mean duration of DM and mean BMI). GBS was multiple in $75 \%$ of diabetics and $72 \%$ of controls, and no significant difference was found between males and females either $(p=0.29)$. About $73.4 \%$ of GBS patients were symptomatic and females were significantly more symptomatic than males ( $80 \%$ vs. $50 \%, \mathrm{p}=0.025$ ).

\section{Discussion}

The prevalence of GBS among Kashmiri female diabetic patients was significantly higher than in non-diabetic female outpatients, but a similar difference was not observed among males. Though no explanation can be offered, it is 
noteworthy that a similar observation was reported from New Zealand (16). The rate of GBS in type-2 Kashmiri diabetics in this study $(40 \%)$ was higher than that reported from Italy (24.8\%) (15) and nearly similar to what was reported from New Zealand (42.1\%) in type-2 diabetics (16), even though our patients were younger than the patients in the other two studies. This might reflect a higher risk of GBS among Kashmiris in general as a result of other contributing risk factors for GBS, such as genetic predisposition, obesity, multiparity and dietary habits with heavy dependency on non-vegetarian food. Diabetic women were 1.8 times more affected than diabetic men (47\% vs. $26 \%, \mathrm{p}=0.01$ ), which agrees with observations of significantly higher prevalence of gallstones among diabetic and non-diabetic women compared to men from all over the world. ${ }^{[10,11,15,18]}$ The higher rate in women is probably due to the effects of sex hormones and pregnancy.

Table 3: Comparison between male and female diabetics with GBS

\begin{tabular}{|l|l|l|l|l|}
\hline & $\begin{array}{l}\text { All GBS } \\
\text { patients }\end{array}$ & $\begin{array}{l}\text { Males with } \\
\text { GBS }\end{array}$ & $\begin{array}{l}\text { Females } \\
\text { with GBS }\end{array}$ & $\begin{array}{l}\text { P- } \\
\text { value }\end{array}$ \\
\hline $\begin{array}{l}\text { Mean } \\
\text { age }( \pm \text { SD) }\end{array}$ & $55.5 \pm 9.7$ & $62.9 \pm \quad 8.5$ & $\begin{array}{l}53.5 \pm 9 \\
\text { years }\end{array}$ & 0.001 \\
\hline $\begin{array}{l}\text { DM duration } \\
( \pm \text { SD })\end{array}$ & $\begin{array}{l}12.5 \pm 7.7 \\
\text { years }\end{array}$ & $\begin{array}{l}13.7 \pm \quad 7.3 \\
\text { years }\end{array}$ & $\begin{array}{l}12.1 \pm \quad 7.9 \\
\text { years }\end{array}$ & 0.49 \\
\hline $\begin{array}{l}\text { Mean } \\
\text { weight }( \pm \mathrm{SD})\end{array}$ & $84.7 \pm 14.9 \mathrm{Kg}$ & $\begin{array}{l}82.5 \pm 12.1 \\
\mathrm{Kg}\end{array}$ & $\begin{array}{l}85.3 \pm 15.6 \\
\mathrm{Kg}\end{array}$ & 0.5 \\
\hline $\begin{array}{l}\text { Mean } \\
\text { BMI } \pm \mathrm{SD})\end{array}$ & $34.78 \pm 6.29$ & $\begin{array}{l}29.46 \pm 4.3 \\
\mathrm{~kg} / \mathrm{m}^{2}\end{array}$ & $\begin{array}{l}36.3 \pm 5.9 \\
\mathrm{~kg} / \mathrm{m}^{2}\end{array}$ & $<0.0$ \\
\hline Symptoms & $73.4 \%$ & $50 \%$ & $80 \%$ & 0.025 \\
\hline $\begin{array}{l}\text { Multiple } \\
\text { GBS }\end{array}$ & $75 \%$ & $64 \%$ & $78 \%$ & 0.29 \\
\hline $\begin{array}{l}\text { Family } \\
\text { history }\end{array}$ & $40.6 \%$ & $15.3 \%$ & $48 \%$ & 0.03 \\
\hline $\begin{array}{l}\text { GBS= gallbladder } \\
\text { standard deviation }\end{array}$ & & & \\
\hline
\end{tabular}

Estrogen induces an increase in cholesterol secretion while progesterone induces reduction in bile acid secretion. ${ }^{[19]}$ These changes eventually lead to supersaturation of bile with cholesterol, which facilitates gallstone formation. However, the higher prevalence we observed among females became statistically insignificant after the age of 50 when females were only 1.4 times more affected than males ( $51.8 \%$ vs. $37.1 \%$,pvalue:0.17) as compared to 5.5 time in patients younger than 50 years old $(42.5 \%$ vs. $7.7 \%, \mathrm{p}=0.02)$ . Age also is a well recognized risk factor for the gallstones in both diabetics and non diabetics. ${ }^{[10,15,16,17]}$ The prevalence of GBS in diabetics older than 40 years was about three times higher than that in younger subjects (42\% vs. $13 \%$ ). Generally, patients with GBS were significantly older than those without GBS (55.5 years vs. 50.5 years, $\mathrm{p}=0.007$ ), and males with GBS were significantly older than females with GBS (62.9 vs. 53.5, p=0.001). The cutoff age beyond which the GBS became significantly higher was 41 years in females $(p=0.01)$ and 53 years in males $(p=0.003)$. About three fourths of GBS patients were symptomatic and females were significantly more symptomatic than males $(80 \%$ vs. 50\%); whether females are really more symptomatic or whether they are just more expressive is not clear. Obesity and overweight are well-known risk factors for the development of gallstones, seemingly due to increased cholesterol synthesis and secretion. ${ }^{[10,15-17,20]}$ The risk is particularly high in women. ${ }^{[21]}$ Obesity was more prevalent in GBS diabetics than in non GBS diabetics (77.8\% vs. $55.2 \%$ ). Diabetics with GBS had a significantly higher BMI than those without GBS $\left(34.78 \mathrm{~kg} / \mathrm{m}^{2}\right.$ vs. 32.2 $\left.\mathrm{kg} / \mathrm{m}^{2}, \quad \mathrm{p}=0.027\right)$. The cutoff BMI associated with significantly increased risk of GBS was $24 \mathrm{~kg} / \mathrm{m}^{2}(\mathrm{p}=0.019)$, which is very near the top of the BMI normal range. Moreover, diabetic women with GBS were significantly more obese than diabetic men with GBS $\left(36.3 \mathrm{~kg} / \mathrm{m}^{2}\right.$ vs. $29.46 \mathrm{~kg} / \mathrm{m}^{2},(\mathrm{p}<.001)$. A family history of GBS has been reported to be an important risk factor for GBS. ${ }^{[10,15,16,22]}$ In our study, a family history of GBS was found in $41.2 \%$ of patients with GBS and in $27.8 \%$ of those without GBS. The difference bordered on statistical significance $(p=0.07)$. We depended on the patients' recall of family members with GBS, and if instead family members were screened with ultrasound the difference might have been more pronounced. Furthermore, a family history of GBS was significantly more prevalent among female patients with GBS $(p=0.011)$. Pregnancy is a major risk factor for the development of gallstones due to qualitative changes in bile and slowing of gallbladder emptying, which promotes bile stasis. ${ }^{[10,16]}$ The mean number of pregnancies of diabetic women with GBS was significantly higher than that of diabetic women without GBS (10.1 vs. 7.7, $\mathrm{p}=0.01)$. In comparison to nulliparus women, diabetic women who had been pregnant at least once before had a significantly higher prevalence of GBS ( $10 \%$ vs. $50.5 \%, \mathrm{p}=0.01)$. This higher prevalence cannot be attributed to age differences alone, as the mean ages of the two groups were not significantly different (46+/-8.9 vs. $40+/-18.7, \mathrm{p}=0.13)$.

Oral contraceptive pills (OCP) are also believed to be associated with a slight increase in the risk of gallstone formation. However, in this study OCP did not seem to increase the risk of GBS in diabetic women, as there was no significant difference in the frequency of using OCP between diabetic women with and without GBS (44\% vs. $42 \%, \mathrm{p}=0.84$ ), and this is similar to results reported from Italy. ${ }^{[15]}$ It has been shown that the frequency of GBS increased only slightly and transiently after starting oral contraceptives, and then the effect disappeared after 10 years. ${ }^{[23]}$ Another study stated that the use OCP only marginally affects the incidence of GBS if at al. ${ }^{[24]}$ On the other hand, the risk of GBS is highest when the estrogen dose is $>50 \mu \mathrm{g} .{ }^{[25]}$

Although the duration of DM in GBS patients (12.5+/- 7.7 years) was slightly longer than the duration in diabetics without GBS (10.6+/-6.8 years), this did not appear to affect the frequency of GBS, as the difference was not statistically significant. The type of treatment does not seem to influence the frequency of GBS as there was no significant difference between GBS and non GBS diabetics regarding the type of treatment (oral, insulin or both). Multiple GBS were detected in $75 \%$ of the cases, and there was no significant difference between diabetics and non-diabetics or males and females regarding multiplicity of stones. 


\section{Conclusion}

Kashmiri diabetic patients had a significantly higher prevalence of cholelithiasis than non diabetics (> 2 times). Female diabetic patients were significantly more affected than males and the prevalence significantly increased with age particularly in males. Older age $(>41$ years in females and $>53$ years in males), high BMI $\left(>24 \mathrm{~kg} / \mathrm{m}^{2}\right)$, female gender, and parity were the most significant risk factors for cholelithiasis in Kashmiri diabetic patients. By contrast, duration of DM, the type of hypoglycemic agent, and the use of OCP did not seem to influence the frequency of GBS among type 2 diabetics. Multiple gall bladder stones were the most common kind of gall bladder stones in diabetics, and the frequency of multiple and single GBS was similar among diabetics and non diabetics.

\section{References}

1. Jorgensen T: Prevalence of gallstones in a Danish population. Am J Epidemiol 126:912-921, 1987

2. Jorgensen T, Kay L, Schultz-Larsen K: The epidemiology of gallstones in a 70-year-old Danish population. Scand J Gastroenterol 25:335-340, 1990

3. Diehl AK: Epidemiology and natural history of gallstone disease. Gastroenterol Clin North Am 20:1-19, 1991

4. Sama C, Labate AMM, Taroni F, Barbara L: Epidemiology and natural history of gallstone disease. Semin Liver Dis 10:149-169, 1990

5. Warren S: The Pathology of Diabetes Mellitus, 2nd ed. Philadelphia, Lea \& Febiger, 1938, pp. 106, 246

6. Lieber MM: The incidence of gallstones and their correlation with other diseases. Ann Surg 135:394-405, 1952

7. Newman HF, Northup JD: The autopsy incidence of gallstones. Int Abstr Surg 109:1-13, 1959

8. Feldman M, Feldman M Jr: The incidence of cholelithiasis, cholesterosis, and liver disease in diabetes mellitus: An autopsy study. Diabetes 3:305-307, 1954

9. Zahor Z, Sternby NH, Kagan A, Uemura K, Vanecek R, Vicbert AM: Frequency of cholelithiasis in Prague and Malmo, an autopsy study.
Scand J Gastroenterot 9:3-7, 1974

10. Jorgensen T. Epidemiology and gallstones Ugeskr Laeger. 2005; 167(24):2610-3.

11. Abdulwahab KMS and Karim A. changing pattern of surgical diseases in Benghazi. Garyounis Med J 1995 ;18:29-31.

12. Elrefai N, Abuzeid I, Elraeid R, Gargoom A. Prevalence of gall bladder stones post-cholecystectomy in diabetic patients. Jamahiriya Med J. $2007 ; 7(1): 42-4$.

13. Hahm JS, Park JY, Park KG, et al. Gallbladder motility in diabetes mellitus using real time ultrasonography. Am J Gastroenterol 1996; 91:2391.

14. Ruhl CE, Everhart JE. Association of diabetes, serum insulin, and Cpeptide with gallbladder disease. Hepatology 2000; 31:299.

15. Pagliarulo M, Fornari F, Fraquelli M, et al. Gallstone disease and related risk factors in a large cohort of diabetic patients. Dig Liver Dis. 2004; 36(2):130-4.

16. Chapman BA, Wilson IR, Frampton CM, et al. Prevalence of gallbladder disease in diabetes mellitus. Dig Dis Sci. 1996; 41(11):22228.

17. Liu CM, Tung TH, Liu JH, Lee WL, Chou P. A community-based epidemiologic study on gallstone disease among type 2 diabetics in Kinmen, Taiwan. Dig Dis. 2004; 22(1):87-91.

18. Attili AF, Carulli N, Roda E, et al. Epidemiology of gallstone disease in Italy: Prevalence data of the multicenter Italian study on cholelithiasis (M.I.COL.). Am J Epidemiol 1995; 141:58.

19. Everson GT. Pregnancy and gallstones. Hepatology 1993; 17:159.

20. Mabee TM, Meger P, DerBesten L, Mason EE. The mechanism of increased gallstone formation in obese human subjects. Surgery 1976; 79:460.

21. Jorgensen T. Prevalence of gallstones in a Danish population. Am J Epidemiol 1987; 126:912.

22. Attili AF, De Santis A, Attili F, Roda E, Festi D, Carulli N. Prevalence of gallstone disease in first-degree relatives of patients with cholelithiasis. World J Gastroenterol 2005; 11(41):6508-11.

23. Thijs C, Leffers P, Knipschild P. Oral contraceptive use and the occurrence of gallstone disease--a case-control study. Prev Med 1993; 22:122.

24. Pannwitz H, Berndt H, Nürnberg D. Prevalence of cholelithiasis in relation to use of hormonal contraceptives. Gastroenterol J 1990; 50(2):78-81.

25. Strom BL, Tamragouri RN, Morse ML, et al. Oral contraceptives and other risk factors for gallbladder disease. Clin Pharmacol Ther 1986; $39: 335$

Copyright: () the author(s), 2019. It is an open-access article distributed under the terms of the Creative Commons Attribution License (CC BY 4.0), which permits authors to retain ownership of the copyright for their content, and allow anyone to download, reuse, reprint, modify, distribute and/or copy the content as long as the original authors and source are cited.

How to cite this article: Nabi S, Hassan Z, Nazima S, Vaqar H. A Case-control Study of Prevalence of Cholelithiasis among Type 2 Diabetic Patients in Kashmir. Asian J. Med. Res. 2019;8(3):SG14-SG17.

DOI: dx.doi.org/10.21276/ajmr.2019.8.3.SG5

Source of Support: Nil, Conflict of Interest: None declared. 